\title{
INVITRO STUDY FOR THE OPTIMAL PRODUCTION OF HEPATITIS B VIRUS SUBVIRAL PARTICLES FOR MEDICAL PURPOSES
}

\author{
Reda A. Suef ${ }^{1}$, Ezz Elden M. Mohamed ${ }^{1}$, Mohamed T. M. Mansour ${ }^{2}$, Mohamed M. S. Farag ${ }^{\text {* }}$ \\ 1 Botany and Microbiology Department, Faculty of Science, Al-Azhar University, Cairo, Egypt, \\ 2 Virology and Immunology Department, National Cancer Institute, Cairo University and Children's \\ Cancer Hospital 57357 \\ *Corresponding Author: mohamed.farag@azhar.edu.eg.
}

\begin{abstract}
During replication of hepatitis B virus (HBV), HBV infected cells secrete infectious viral particles and large quantities of subviral particles which are assembled from surface protein without a viral genome. For the current study, the cell line of HepG2.2.15 genetically integrated with the HBV surface region was cultured as an expression system for in vitro production of hepatitis B virus subviral particles (HBVsvp) at different time for commercial purposes. Recorded Results showed that culturing and incubation of HepG2.2.15 cells over 7 days incubation period resulted in continuous secretion of HBsvp in the supernatant. ELISA's quantitative measurement of hepatitis B surface antigen reported that the highest titer of virus was day seven. Quantitative detection of HBsAg by ELISA indicated that the highest virus titer was at day seven. According to their size, subviral spherical particles recognized by a diameter of $22 \mathrm{~nm}$. In conclusion, in vitro cultivation and incubation of HepG2.2.15 for secretion of HBsAg may be used in studying HBV replication thus, opening a new era for various studies from basic virology, in vitro diagnosis, to drug development against HBV genotypes.
\end{abstract}

Keywords: Hepatitis B virus subviral particles; HepG2.2.15 cell line; Polyethylene glycol; Virion-based vaccine candidate

\section{INTRODUCTION}

Hepatitis B virus (HBV) is a member of the family Hepadnaviridae and is a small, enveloped DNA virus whose tropism is limited to the hepatocyte causing hepatocellular necrosis and inflammation [1]. HBV infection can be either acute or chronic, and the associated illness ranges in severity from asymptomatic to symptomatic, progressive disease [2]. Data from the World Health Organization reveals that an estimated 257 million people $(3.5 \%)$ globally are living with chronic HBV infection, 1.34 million deaths (a number comparable to deaths caused by tuberculosis bacteria and more than infection those caused by HIV) due to chronic liver disease $(720,000$ deaths due to cirrhosis) and liver cancer $(470,000$ deaths due to hepatocellular carcinoma) [3].

Hepatitis B virion has three various structures, Dane particle (42 nm), spherical (20 $\mathrm{nm})$ and filamentous (22 nm) particles [4]. All three particles sharing a common HBsAg as an envelope [5]. The spherical and filamentous particles (termed by subviral particles) are composed of HBsAg and host-derived lipids without the HBV genome; thus, they are noninfectious while the Dane particle is a complete infectious sphere HBV virion with $42 \mathrm{~nm}$ [5]. HBsAg exists in three forms: small (S), medium (M) and large (L). The $\mathrm{S}$ domain is common to all three proteins, while the $\mathrm{M}$ protein has an additional $\mathrm{N}$ terminal domain (PreS2) and L, two additional domains (PreS1 and PreS2). L-HBsAg is a minor component of SVP, but a main component of VP [6].

During the acute phase of the viral infection, non-infectious subviral particles can be present in the serum of infected individuals at up to 100,000 folds over the complete virion (at $1014 / \mathrm{mL}$ ) [7]. Whereas the main function of complete virions is to deliver the viral genome 
to a newly infected cell, The role of subviral particles in infection with the hepatitis B virus was largely ignored but it has been proposed that HBsAg in SVP serves as decoy to reduce the antiviral effects of neutralizing antibodies increasing the ability of the infectious particles to reach susceptible cells and thus lead to the immune tolerance needed to sustain a long-term chronic infection [8]. It has also been shown that artificial SVP produced by transfected Huh7 cells had little impact on viral entry subsequently, did not inhibit the HBV to infect primary human hepatocytes [9]. A study of duck hepatitis B virus SVPs showed that the SVPs acting to either enhance or inhibit infection based on the ratio of SVP-toinfectious-particles [10].

Historically, the abundance of subviral particles has been very useful as a convenient marker for monitoring HBV infection, screening of blood donors, and measuring antiviral treatment response [11]. Similarly, the $\mathrm{Au}$ antigen particles (contains $\mathrm{HbsAg}$ particles), collected directly from infected patients' pooled plasma, formed the basis of the first generation of HBV vaccine, which proved to be highly effective [12]. Due to the potential safety concerns surrounding human plasma use, this highly successful vaccine was replaced by the current recombinant (2nd generation) HBV vaccine containing only one of the HBV envelope proteins, $\mathrm{S}$ without capsid protein. While in most cases it has been proven safe and efficient, the recombinant $S$ vaccine does not induce an adequate response in about 5-10\% of normal individuals [13]. Also, since the recombinant vaccine mainly elicits an antibody response targets a single specific epitope, HBV may develop mutations in this epitope to escape the antibodies induced by the vaccine [14].

To overcome the limitations of the current vaccine escape issue, it is urgently needed to develop a possible 3 rd generation HBV vaccine which can be achieved by producing these subunits in a very high quantities including different forms of SVPs instead of one type and at the same time more safe than SVPs obtained from the sera of infected individuals which contain infectious virus as well as SVPs. There is also a need for highly concentrated amounts of HBsAg to develop a sensitive and effective immunoassay to detect antibodies to HBs either they formed against native $\mathrm{HBV}$ infection or from vaccination [15].

So, according to the vital role of HBsvp, the main purpose of this study was in vitro propagation of HBsvp in a highly concentrated amount by using HepG2.2.15 cell lines transfected with HBV Surface region as an expression system for antigenic subviral particles. For this purpose, we optimized the conditions for highest production rate within a specific time frame then investigate morphological and serological characters of secreted HBsAg that may prove to be beneficial as diagnostic markers and possibly, as an SVPs -based vaccine candidate that finally contributed to improved control of chronic HBV infections.

\section{MATERIALS AND METHODS:}

\subsection{HepG2.2.15 cell line maintenance}

Human hepatocyte carcinoma HepG2.2.15 cell line incorporated with $\mathrm{HBV} S$ domain obtained from a culture collection, (ECACC). Maintenance of the cells was carried out initially by culturing in $10 \mathrm{ml}$ of complete Williams medium (Lonza, Swiss), supplemented with $10 \%(\mathrm{v} / \mathrm{v})$ fetal bovine serum (FBS) (Serolab, Brazil), $100 \mathrm{U} / \mathrm{ml}$ Penicillin, $100 \mu \mathrm{g} / \mathrm{ml}$ streptomycin, $2 \mathrm{mM} \mathrm{L-}$ glutamine (Lonza, Swiss), $250 \mu$ insulin $(5 \mu \mathrm{g} / \mathrm{ml}) \quad$ (Sigma, China), and $250 \mu \mathrm{l}$ hydrocortisone (Sigma, China). Then, HepG 2.2.15 were incubated overnight. To assessed $80 \%$ confluency degree of cultivation, cell monolayer washed twice, cells were harvested by trypsinization, centrifuged at $1500 \mathrm{rpm}$ for 5minutes, the supernatant discarded, the cells pellet resuspended in $1 \mathrm{ml}$ fresh growth medium for counting. The total number of cells per milliliter and percent of viability was determined using a hemocytometer, and trypan blue vital stain. The number of viable (seen as bright cells) were counted [16]. 


\subsection{Growth curve}

For evaluating the growth characteristics (cell viability and activity) of a HepG 2.2.15 cell line, a growth curve was generated which was constructed from samples taken at different time intervals (from day one to day eight) throughout the growth cycle depending on enzyme-based assay using MTT colorimetric method that measure mitochondrial dehydrogenase activities in the living cells [17]. It was described as the following:

HepG2.2.15 initially cultured in $75 \mathrm{~cm} 2$ flasks at a seeding density of $3 \times 105$ viable cells $/ \mathrm{ml}$. after assessing the $>80 \%$ of confluency for HepG2.2.15, density and viability of the cells using a hemocytometer was $(19 \times 106)$. After counting, cells were distributed at serial two-fold dilutions of cells $(1.25 \times 103$ to $640 \times 103)$ in $200 \mu$ l culture medium per well in duplicate for 7 days, cells were incubated for 24 hours at $37^{\circ} \mathrm{C}$. A $200 \mu \mathrm{L}$ of MTT Reagent added to each well of each day separately. The plate incubated in $\mathrm{CO} 2$ incubator for 2 to 4 hours at $37{ }^{\circ} \mathrm{C}$. The cells examined for the appearance of punctate, intracellular precipitate using an inverted microscope. When the purple precipitate was clearly visible under the microscope, $200 \mu 1$ of detergent reagent (DMSO) added to all wells, left in the dark for 2 to 4 hours at room temperature for dissolving formazan salt. Eventually, the absorbance was measured in each well by ELISA at a wavelength between 570 and $590 \mathrm{~nm}$ with a reference wavelength of $650 \mathrm{~nm}$.

\subsection{Optimizing the Production of SVP}

To address the optimum conditions for determination of the highest productivity of Hepatitis B Subviral Particles (HBsvp) over 7 days cells culturing. The HepG2.2.15 cell suspension produced from cell culture was distributed into three groups. Each group contains seven flasks $(25 \mathrm{~cm} 2)$, each of which represents 7 days. A $0.5 \times 106$ cell/flask were added as initial seeding density of cell suspension for all groups then incubated for up to 7 days. Subsequently, the production of
HBsvp was determined for different days by ELISA including the following days1, 2, 3, 4, $5,6,7$ for optimizing the optimal viral production.

\section{Characterization of Subviral Particles of Hepatitis B \\ 3.1.HBsvp Concentration}

Cell culture supernatant (containing HBsvp) at separate days (from1 to 7) was harvested for viral concentration by polyethylene glycol (PEG) protocol [18]. The concentration starting with incubation for all samples with $40 \%$ Polyethylene glycol PEG (Nice, India) at $4{ }^{\circ} \mathrm{C}$ for overnight. Then, the medium was centrifuged for two hours at $4{ }^{\circ} \mathrm{C}$ at $4000 \mathrm{rpm}$ on the second day, pellet have been resuspended in a mix of $(75 \%) 1 x$ PBS and FBS $(25 \%)$, subsequently incubated at 4 ${ }^{\circ} \mathrm{C}$ for second night. The isolates were collected on the third day, and centrifuged at $4000 \mathrm{rpm}$ at $4{ }^{\circ} \mathrm{C}$ for 20 minutes. The isolates (which contain the concentrated HBsvp) were collected after centrifugation and stored at $-20{ }^{\circ} \mathrm{C}$ for quantifying by ELISA.

\subsection{Serological characterization of HBsvp}

HBsvp containing supernatant (before and after concentration with PEG) were assayed for qualitative and quantitative detection of HBsAg by ELISA (Cam Tech Medical). Following the manufacturer's instructions [19], The loading plate stage began with the addition of $50 \mathrm{ul}$ of (Negative Control, Positive Control, 21 specimens (represents 3 groups) and AntiHBsAg conjugate into each well used. The plate incubated at $37^{\circ} \mathrm{C}$ for $30 \mathrm{~min}$, washed 6 times with the working washing solution, $50 \mathrm{ul}$ of Substrate solution distributed on each well and incubated for 10 minutes at $37^{\circ} \mathrm{C}$. Finally, the reaction was stopped by adding $50 \mathrm{ul}$ of Blocking Reagent to each well and the color developed on the microplate reader readied at $450 \mathrm{~nm}$.

\subsection{Morphological characterization}

For estimating the size and shape of the different viral structures (Dane, spherical and filamentous structures), chronic HBV patient 
positive samples and HBsvp containing supernatant was examined through transmission electron microscopy TEM (JEOL 1010, nanotechnology center, Egypt) at $200 \mathrm{KV}$ volt. The image is created after staining viruses with negative stain onto the carbon-coated copper grid, dried and loaded onto a specimen holder for analysis by TEM [20].

\section{RESULTS}

\subsection{Examination of HepG2.2.15}

The HepG2.2.15 cell were morphologically observed as elongated cylindrical HepG2.2.15 with an increase in proliferation rate starting from in day 1 till day 7 (photograph 1).

\subsection{Characterization of Subviral Particles of Hepatitis B}

Concentration of the SVPs by ELISA
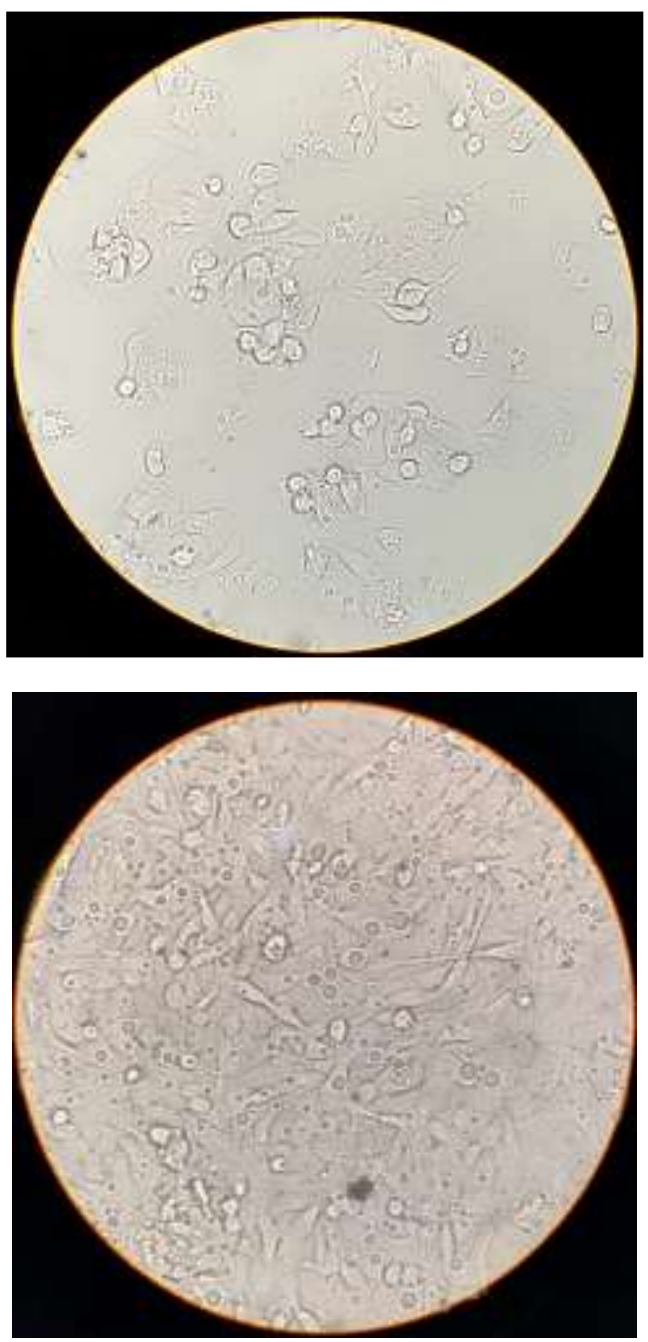

Photograph 1 shows the morphology HepG2.2.15 cell line under inverted phase contrast light microscope with 400x. day 1 (A); day 3 (B); day 5 (C); day 7(D).
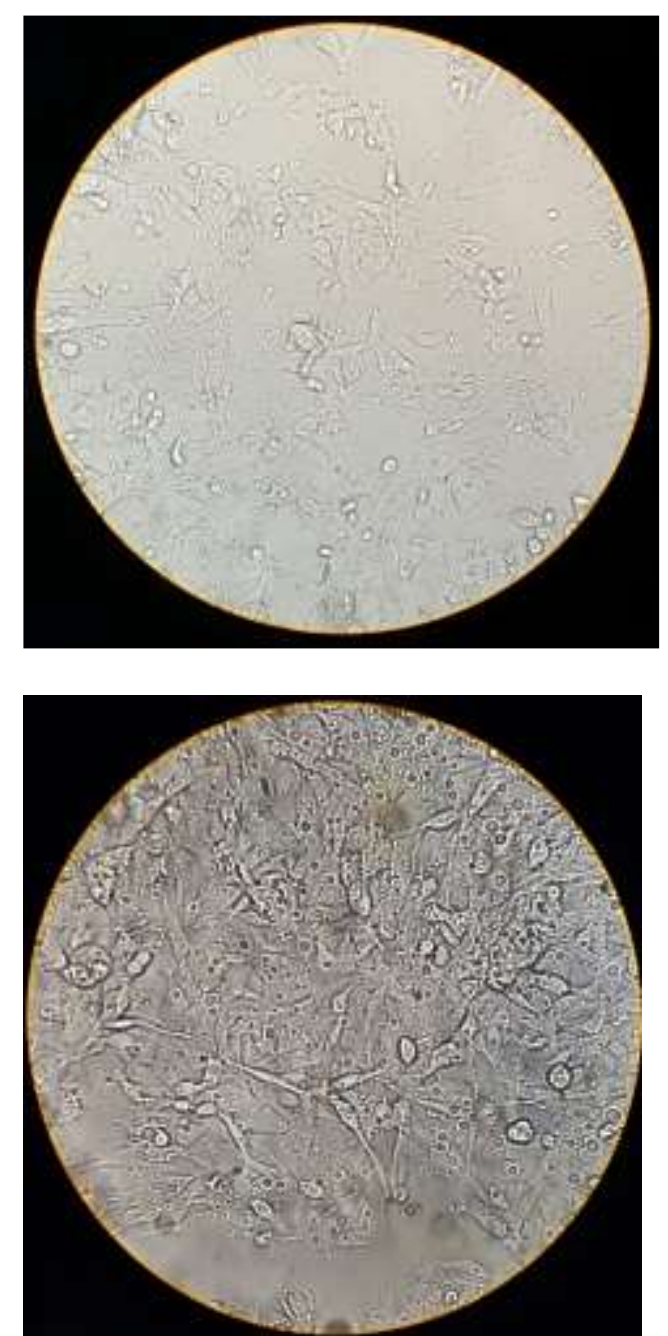

confirmed that the highest secretion of the virus was observed on day 7 after culturing and incubation of each different three groups. The average titre of virus was $0.943,1.283,1.426$ (OD) for the first, second, and third groups (Figure 2).

\subsection{Characterization of Subviral Particles of Hepatitis B}

Concentration of the SVPs by ELISA confirmed that the highest secretion of the virus was observed on day 7 after culturing and incubation of each different three groups. The average titre of virus was $0.943,1.283,1.426$ (OD) for the first, second, and third groups (Figure 2).

\section{HBsvp concentration}

After propagation of HBsvp containing 
supernatant, poly ETG protocol was used for concentration of HBsvp in three groups among 7 days, and quantitative detection of $\mathrm{HBsAg}$ were assayed by ELISA, the resulted optical density for samples showed that the highest viral concentration was day 7 concentrated sample (2.327 O.D.) after cultivation of HepG2.2.15 for seven days compared to concentrated SVP in day one

\subsection{Growth curve for HepG 2.2.15 Adherent Cell Lines}

Absorbance measurements for HbsAg with different cell number cultured for seven days indicated that the highest concentration was at day seven (Figure 4).

\subsection{Electron microscopy: HBsvp morphological characterization}

Observation by transmission electron microscopy (JEOL 1010, nanotech center, Egypt) at $200 \mathrm{KV}$ evaluate both the shape and size of chronic HBV patient control sample and SVP secreted from HepG2.2.15 cell line. Control sample appeared as two form of spherical particles (Dane particle $42 \mathrm{~nm}$ ) and spherical $(20 \mathrm{~nm})$, while the SVP produced from HepG2.2.15 observed as spherical (20 $\mathrm{nm})$ particles confirming the absence of complete infectious Dane particles (Figure 5)

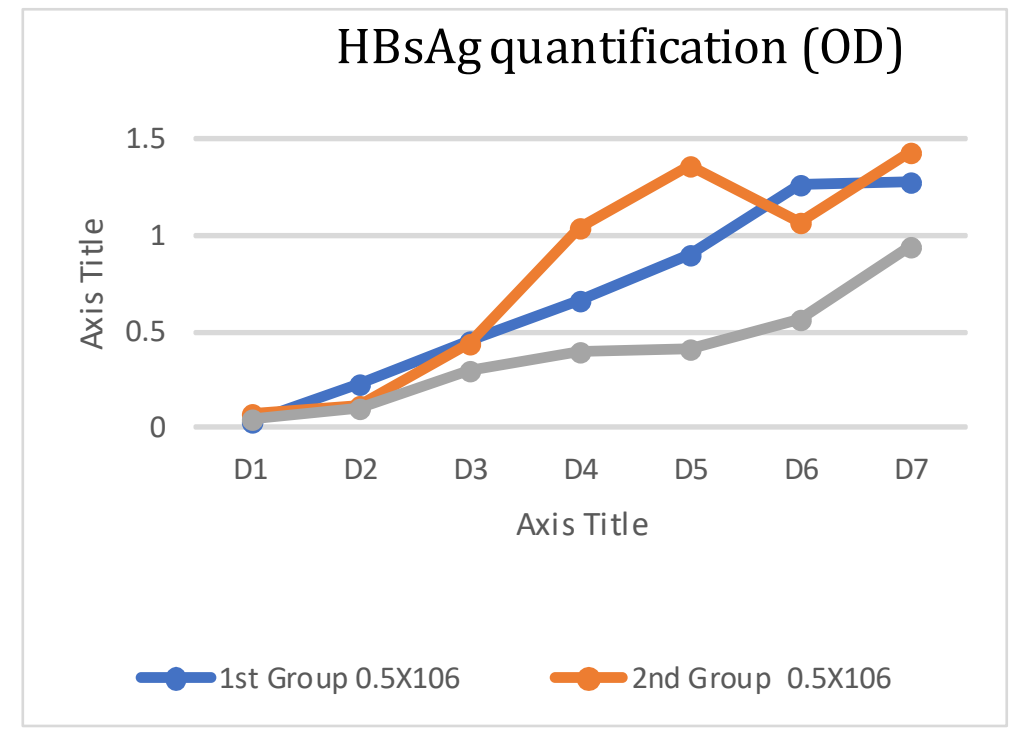

Figure2. shows ELISA measurement of HBsAg titers in the HepG2.2.15 supernatant for 3 groups at different days (D1:D7). The figure indicates the Highest Secretion of Virus (day seven) and the lowest Secretion (day one).

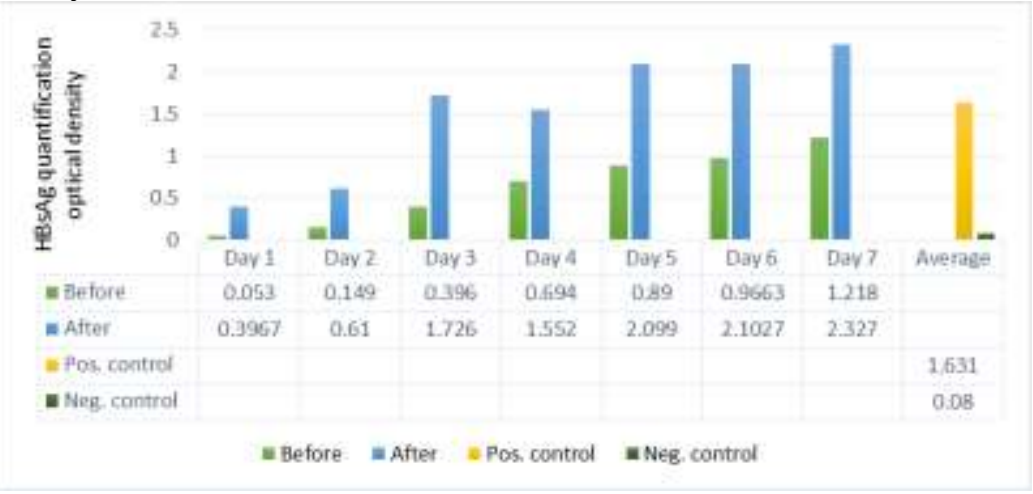

Figure 3. Shows ELISA measurement for HBsAg before and after concentration for different supernatant samples 


\section{DISCUSSION \\ 100,000-fold over the complete virions}

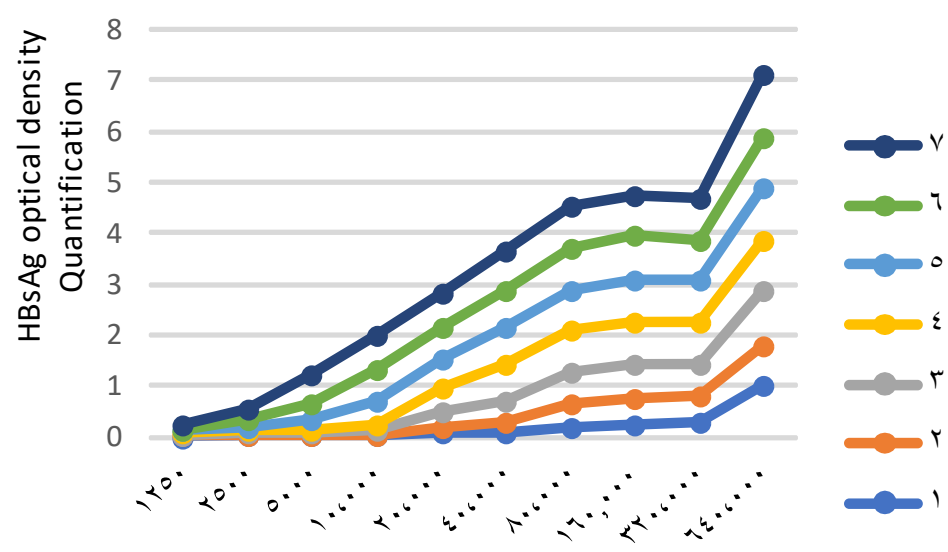

HepG2.2.15 cell line density

Figure 4: Showed ELISA measurement for HbsAg with different cell density for seven days.
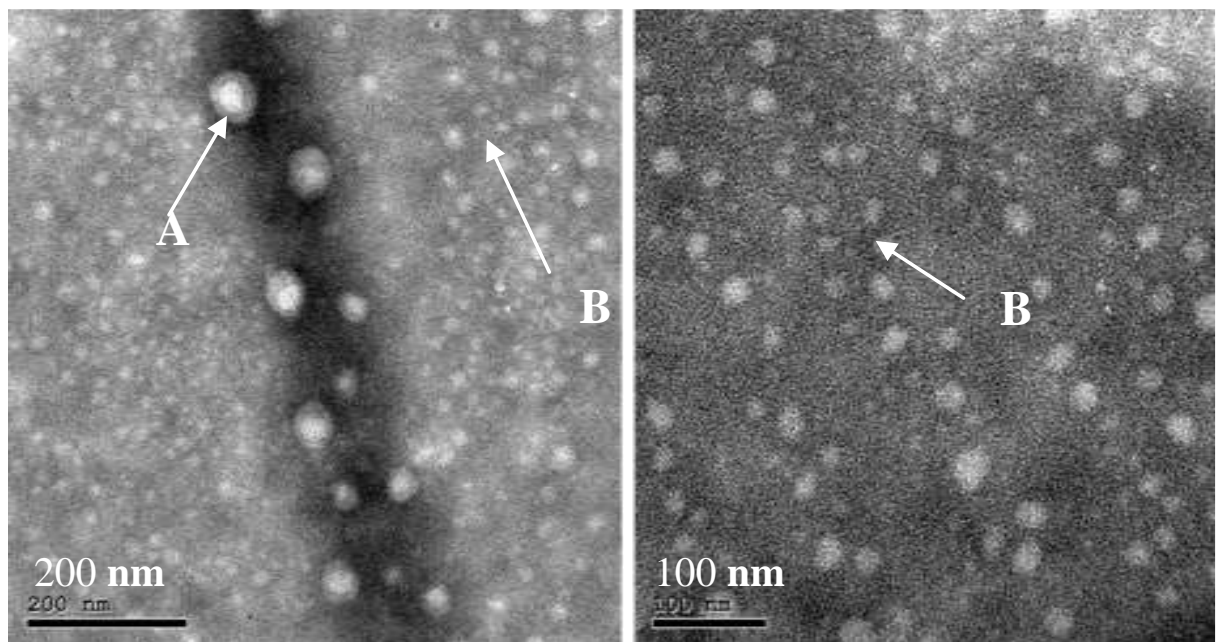

Figure 5. shows transmission electron photographs represent the size and morphology of HBV And HBVsvp derived from cell line HepG2.2.15. I) The positive sample for HBV serum includes (A: 42nm Dane particle), (B: 22nm subviral spherical particle. II) The HepG2.2.15 cell line supernatant includes (B: 22nm subviral spherical particle II).

A major characteristic of HBV-replicating cells is the secretion of large amounts of complete and incomplete viral particles. complete virion are spheres, $42 \mathrm{~nm}$ in diameter, and usually present in the blood of infected patients at $109 / \mathrm{mL}$ [21]. By contrast, incomplete subviral HBV particles, of which two main types are identified, either lack the genome and capsid, or just the genome.The first type is the typical $20 \mathrm{~nm}$ diameter HBsAg spheres and filaments (HBsAg particles), which are constructed exclusively from of surface antigenic proteins and with a ratio up to
(1014/mL) [22]. The second type is the newly described empty (genome-free) virions, which have been assembled from outer surface proteins surrounding the viral capsid without genome and usually present in the blood of infected people at 100 times higher rates than full virions $(1011 / \mathrm{mL})$ [23].

In the present study, HepG2.2.15 cell culturing in $10 \%$ complete williams medium supplemented with growth factors hydrocortisone and insulin for 8 days resulted in an increase in proliferation rate till day 7 compared to day 1 , day 8 represent the 
stationary state for the cells without further division, cells were morphologically observed as elongated cylindrical cells.

optimization of SVP production starting with distribution of HepG2.2.15 cell suspension into three groups (each group contains seven flasks) represents 7 day with initial seeding density of cell suspension for all groups $0.5 \times 106$ cell/flask, the highest production rate of HBsvp after incubation for up to 7days in $7 \mathrm{ml}$ of cell culture supernatant (containing HBsvp) was determined quantitively by ELISA . Our findings showed that the highest titer of the virus was day7 with average virus titre 1.217 (OD) for first, second, and third groups by $95.83 \%$ increase compared to $4.17 \%$ day 1 production rate that represent the lowest virus titre, with average virus titre 0.053 (OD) for the first, second, and third groups. We concentrated the SVP in a high titer. In this experiment each run was performed on average for different supernatant obtained. Also, for run 7 , the highest concentrations of SVP were at day 7 with 2.327 (OD).

In comparison to positive HBV samples which exhibit two particle types: Dane particle in $42 \mathrm{~nm}$ and subviral spherical particle in 22 $\mathrm{nm}$, transmission electron photographs shows that HBVsvp secreted from HepG2.2.15 cell line observed as incomplete HB subviral sphere particles with $22 \mathrm{~nm}$ diameter size. This sphere type of svp represent the classical HBsAg (either lacks both genome and capsid or just the genome) and found in abundant manner.

HBsvp in vitro production by transfection procedures was important for several reasons. Initially is they being not contagious compared to the isolation from the sera of infected individuals that contains both infectious virus as well as SVP; so, it can be safely handled in accordance with previous reports [24-28]. HBVsvp could also be produced in about absolute quantities, and can also be produced for the different genotypes and subtypes [29]. Additionally, SVPs can be assembled in various ways that contain only the HBV $S$ protein or those that contain both the $\mathrm{S}$ and $\mathrm{L}$ proteins[9].

For the present study, selection of the cell line HepG2.2.15 transfected with HBV surface region as it is a stably producing SVPs, has been commonly used for drug screenings, and more favorable than the primary human hepatocytes and dHepaRG cell culture systems which are known by limited availability, high variability, loss of hepatocyte function in culture [30]. Also, invitro cell culture models as HepG2 cells constitute a potent cell model for HBV and has been used in an increasing number of studies [31-33] However, the system has some limitations. HepG2 cells are transformed and have chromosomal abnormalities as well as defects in some intracellular signaling pathways. In addition, HepAD38 cell line produced a relatively small quantities of SVP compared to HBV particles [9].

Since the viral envelope protein structure on the surface of empty virions possibly resembles that of full virions but are noninfectious, because they assemble without containing the genetic material, it would provide the possibility for the use as a prophylaxis before infection or used with nonresponders to the current vaccine in agreement with a previous relevant reports [34,35].

\section{CONCLUSION}

Using HepG2.2.15 cell line as an expression system in $10 \%$ complete williams E medium supplemented with growth factors as hydrocortisone and insulin gives priority in continual secretion of large quantities of main types of HB subviral particles (either lacking the genome and capsid or lacking only the genome) rather than widely used hepatoma cell lines not susceptible to HBV infection. Such results put a spotlight on HBsAg protein that may be useful as diagnostic markers, and maybe as a potential vaccine candidate as the immunogenic agents to induce the defensive antibody (anti-HBs) fighting HBV infection. It is important to note that further improvement 
and optimization of the conditions for the hepatoma cell culture are needed.

\section{ACKNOWLEDGMENTS}

We thank all members of molecular biology unit at Children's Cancer Hospital Egypt-57357 (CCHE) for the continuous support to accomplish this work.

\section{Author Disclosure Statement}

The authors report no conflicts of interest in this work.

\section{REFERENCES}

[1] Guidotti, L. G. and Chisari, F. V (2006) 'Immunobiology and pathogenesis of viral hepatitis', Аnnu. Rev. Pathol. Mech. Dis. Annual Reviews, 1, pp. 23-61.

[2] Trépo, C., Chan, H. L. Y. and Lok, A. (2014) 'Hepatitis B virus infection', The Lancet. Elsevier, 384(9959), pp. 2053-2063.

[3] World Health Organization. Global Hepatitis Report, 2017 (WHO, Geneva, 2017).

[4] Liang, T. J. (2009) 'Hepatitis B: the virus and disease', Hepatology. Wiley Online Library, 49(S5), pp. S13-S21.

[5] Doo, E. C. and Ghany, M. G. (2010) 'Hepatitis B virology for clinicians', Clinics in liver disease. Elsevier, 14(3), pp. 397-408.

[6] Guo, H., \& Cuconati, A. (Eds.). (2017). Hepatitis B Virus: Methods and Protocols. vol. 1540, chapter 15. P193-195. DOI 10.1007/9781-4939-6700-1-2 @ Springer

[7] Baumert, T. F., Meredith, L., Ni, Y., Felmlee, D. J., McKeating, J. A., \& Urban, S. (2014). Entry of hepatitis B and C viruses - recent progress and future impact. Current opinion in virology, 4, 58-65.

[8] Rydell, G. E., Prakash, K., Norder, H., \& Lindh, M. (2017). Hepatitis B surface antigen on subviral particles reduces the neutralizing effect of anti-HBs antibodies on hepatitis B viral particles in vitro. Virology, 509, 67-70.

[9] Chai, N., Chang, H. E., Nicolas, E., Han, Z., Jarnik, M., \& Taylor, J. (2008). Properties of subviral particles of hepatitis B virus. Journal of virology, 82(16), 7812-7817.

[10] Lamontagne, R. J., Bagga, S., \& Bouchard, M. J. (2016). Hepatitis B virus molecular biology and pathogenesis. Hepatoma research, 2, 163 $186 . \quad$ https://doi.org/10.20517/23945079.2016 .05

[11] $\mathrm{Hu}$, J., \& Liu, K. (2017). Complete and incomplete hepatitis B virus particles: formation, function, and application. Viruses, 9(3), 56

[12] Blumberg, B. S. (1977) 'Australia antigen and the biology of hepatitis B', Science. JSTOR, 197(4298), pp. 17-25.

[13] Bertoletti, A., \& Ferrari, C. (2016). Adaptive immunity in HBV infection. Journal of hepatology, 64(1), S71-S83.

[14] Lai, M. W., Lin, T. Y., Tsao, K. C., Huang, C. G., Hsiao, M. J., Liang, K. H., \& Yeh, C. T. (2012). Increased seroprevalence of HBV DNA with mutations in the s gene among individuals greater than 18 years old after complete vaccination. Gastroenterology, 143(2), 400407.

[15] Heijtink, R., Bergen, P. van, Melber, K., Janowicz, Z., \& Osterhaus, A. D. M. (2002). Hepatitis B surface antigen (HBsAg) derived from yeast cells (Hansenula polymorpha) used to establish an influence of antigenic subtype (adw2, adr, ayw3) in measuring the immune response after vaccination. Vaccine, 20(17), 2191-2196.

[16] Freshney, R. I. (2015). Culture of animal cells: a manual of basic technique and specialized applications. John Wiley \& Sons.

[17] Stoddart, M. J. (1st Ed.). (2011). Mammalian cell viability: methods and protocols (pp. 1-7). New York: Springer.

[18] Farag, M. M., Peschel, G., Müller, M., \& Weigand, K. (2019). Characterization Of The Interaction Between Subviral Particles Of Hepatitis B Virus And Dendritic Cells-In Vitro Study. Infection and Drug Resistance, 12, 3125

[19] Liu, Y. P., \& Yao, C. Y. (2015). Rapid and quantitative detection of hepatitis B virus. World journal of gastroenterology, 21(42), 11954-11963. https://doi.org/10.3748/wjg.v21.i42.11954

[20] Dane, D. S., Cameron, C. H., \& Briggs, M. (1970). Virus-like particles in serum of patients with Australia-antigen-associated hepatitis. The lancet, 295(7649), 695-698.

[21] Hu, J. (2016). Hepatitis B virus virology and replication. In Hepatitis B virus in human diseases (pp. 1-34). Humana Press, Cham.

[22] Ning, X., Nguyen, D., Mentzer, L., Adams, C., Lee, H., Ashley, R., ... \& Hu, J. (2011). Secretion of genome-free hepatitis B virussingle strand blocking model for virion morphogenesis of para-retrovirus. PLoS pathogens, 7(9).

[23] Luckenbaugh, L., Kitrinos, K. M., Delaney IV, W. E., \& Hu, J. (2015). Genome - free hepatitis $\mathrm{B}$ virion levels in patient sera as a potential 
marker to monitor response to antiviral therapy. Journal of viral hepatitis, 22(6), 561570.

[24] Ganem, D. and Prince, A. M. (2004) 'Hepatitis $\mathrm{B}$ virus infection - natural history and clinical consequences', New England Journal of Medicine. Mass Medical Soc, 350(11), pp. 1118-1129.

[25] Glebe, D. and Urban, S. (2007) 'Viral and cellular determinants involved in hepadnaviral entry', World journal of gastroenterology: WJG. Baishideng Publishing Group Inc, 13(1), p. 22.

[26] Gudima, S., He, Y., Meier, A., Chang, J., Chen, R., Jarnik, M., ... \& Taylor, J. (2007). Assembly of hepatitis delta virus: particle characterization, including the ability to infect primary human hepatocytes. Journal of virology, 81(7), 36083617.

[27] Sells, M. A., Chen, M. L. and Acs, G. (1987). Production of hepatitis B virus particles in Hep G2 cells transfected with cloned hepatitis B virus DNA. Proceedings of the National Academy of Sciences. National Acad Sciences, 84(4), pp. 1005-1009.

[28] Singer, G. A., Zielsdorf, S., Fleetwood, V. A., Alvey, N., Cohen, E., Eswaran, S., ... \& Fayek, S. A. (2015, March). Limited hepatitis b immunoglobulin with potent nucleos (t) ide analogue is a cost-effective prophylaxis against hepatitis b virus after liver transplantation. In Transplantation proceedings (Vol. 47, No. 2, pp. 478-484). Elsevier.

[29] Oka, Y., Fazle Akbar, S. M., Horiike, N., Joko, K., \& Onji, M. (2001). Mechanism and therapeutic potential of DNA - based immunization against the envelope proteins of hepatitis B virus in normal and transgenic mice. Immunology, 103(1), 90-97.

[30] Allweiss, L., \& Dandri, M. (2016). Experimental in vitro and in vivo models for the study of human hepatitis B virus infection. Journal of Hepatology, 64(1).

[31] Li, J., Zong, L., Sureau, C., Barker, L., Wands, J. R., \& Tong, S. (2016). Unusual features of sodium taurocholate cotransporting polypeptide as a hepatitis B virus receptor. Journal of virology, 90(18), 8302-8313.

[32] Ni, Y., Lempp, F. A., Mehrle, S., Nkongolo, S., Kaufman, C., Fälth, M., \& Sültmann, H. (2014). Hepatitis B and D viruses exploit sodium taurocholate co-transporting polypeptide for species-specific entry into hepatocytes. Gastroenterology, 146(4), 1070-1083.

[33] Yan, H., Zhong, G., Xu, G., He, W., Jing, Z.,
Gao, Z., .\& Fu, L. (2012). Sodium taurocholate cotransporting polypeptide is a functional receptor for human hepatitis B and D virus. elife, 1, e00049.

[34] Farag, M. M., Hoyler, B., Encke, J., Stremmel, W., \& Weigand, K. (2010). Dendritic cells can effectively be pulsed by HBVsvp and induce specific immune reactions in mice. Vaccine, 29(2), 200-206.

[35] Huang, Y., Chen, Z., Jia, H., Wu, W., Zhong, S., \& Zhou, C. (2006). Induction of Tc1 response and enhanced cytotoxic $\mathrm{T}$ lymphocyte activity in mice by dendritic cells transduced with adenovirus expressing HBsAg. Clinical Immunology, 119(3), 280-290.

$$
\begin{aligned}
& \text { دراسة معمليه للإنتاج الأمثل للجزيئات تحت الفيروسية } \\
& \text { لفيروس التهاب الكبد الوبائي ب للأغراض الطبية } \\
& \text { رضا عبد العزيز سيوف1 ، عز الاين محمود } 1 \text { ، } \\
& \text { محمد طارق منصور2 ، محمد منصور سعد فرجا } \\
& \text { 1- قسم النبات ، كلية العلوم ، جامعة الازهر }
\end{aligned}
$$

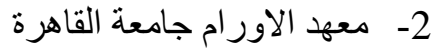

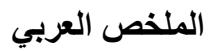

، أثناء تكاثر فيروس التهاب الكبد البائي(HBV) تفرز الخلايـا المصـابة جزيئات فيروسية معديـة وكميـات

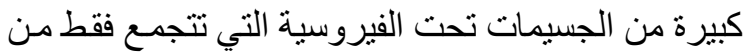

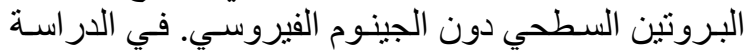

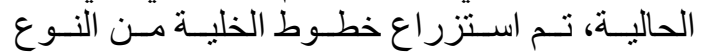

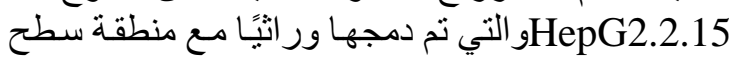

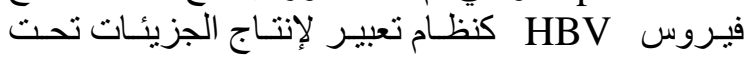

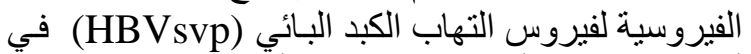

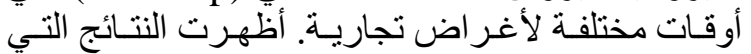

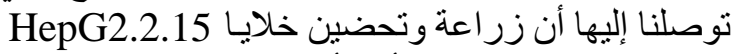

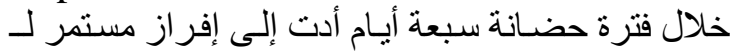
HBsvp HBsAg بواسطة ELSA أظهـر أن أعلى معيـار

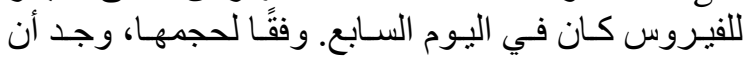

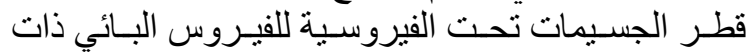

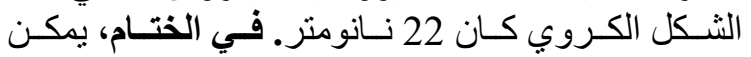

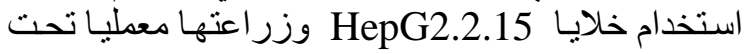

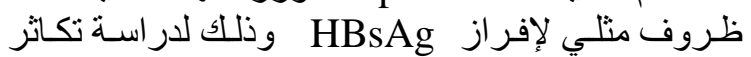

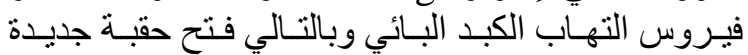

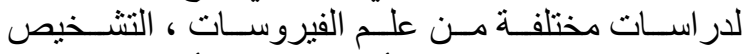

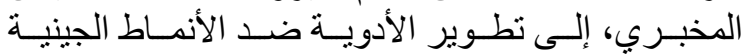
المختلفة لفيروس التهاب الكبد البائي 